\title{
A profile of nurses in psychiatric units: Istanbul sample
}

\author{
(1) Fahriye Oflaz, ${ }^{1} \oplus$ Nur Elçin Boyacıoğlu, ${ }^{2} \oplus$ Sevil Yılmaz, ${ }^{3} \odot$ Özge Sukut, ${ }^{3}$ \\ (1) Nareg Doğan, ${ }^{4}$ () Semra Enginkaya ${ }^{5}$ \\ 'Department of Psychiatric Nursing, Koç University School of Nursing, İstanbul, Turkey \\ ${ }^{2}$ Department of Gerontology, İstanbul University-Cerrahpaşa Faculty of Health Sciences, İstanbul, Turkey \\ ${ }^{3}$ Department of Mental Health and Psychiatric Nursing, İstanbul University-Cerrahpaşa Florence Nightingale Faculty of Nursing, \\ İstanbul, Turkey \\ ${ }^{4}$ Department of Nursing, Bezmialem Vakıf University Faculty of Health Sciences, İstanbul, Turkey \\ ${ }^{5}$ Department of Psychiatry, Bakırköy Dr. Mazhar Osman Mental Health and Neurological Diseases Hospital, İstanbul, Turkey
}

\begin{abstract}
Objectives: Nurses are the backbone of the workforce in mental healthcare. However, profile studies of nurses working in mental health services are limited, and provide inadequate qualitative and quantitative evidence about the characteristics, roles and functions of nurses who work in psychiatric settings. The aim of this study was to examine and provide a profile of nurses working in Istanbul psychiatric care units.

Methods: A descriptive and cross-sectional design was used to analyze the personal characteristics, work conditions, and job-related experiences of 307 nurses working in psychiatric service units in Istanbul in 2018-2019. Data were collected using a 46-question digital survey of personal and professional experiences, services performed, and work conditions. Results: The nurses' responses revealed that they felt that the patient/nurse ratio was insufficient and that the physical environment was inadequate, there was a lack of sufficient safety, and insufficient support personnel. Nurses still fulfill a very traditional role in psychiatric settings.

Conclusion: This study illustrates some of the work-related concerns and experiences of nurses serving in psychiatric service units. A greater focus on personal, recovery-centered care according to evidence-based standards for the patient/nurse ratio and other international criteria and knowledge is needed.
\end{abstract}

Keywords: Nursing workforce; psychiatric nursing; psychiatric services.

$\mathrm{N}^{\mathrm{s}}$ urses working in mental health services at all levels are professionals who provide patients and their relatives with the care they need and accompany them on what can be a very challenging journey. Therefore, it is important that these nurses are equipped with knowledge and skills specific to this field. The general nursing literature indicates that advanced training and a large number of qualified nurses leads to better patient outcomes. The rates of mortality, duration of hospital stay, and readmission to hospital after discharge have been shown to decrease when the majority of nurses have a minimum of a baccalaureate degree. ${ }^{[1-3]}$ However, the literature specific to psychiatric care remains weak. Studies of psychiatric nursing have indicated that it is very common to see that nurse-patient staffing issues, a chaotic environment in acute settings, and a heavy workload prevent nurses from performing the optimal therapeutic interactions and activities in psychiatric units. ${ }^{[4-6]}$

The majority of the international research on psychiatric health services has mainly focused on the number and qual-

Address for correspondence: Fahriye Oflaz, Koç Üniversitesi Hemşirelik Fakültesi, Davutpaşa Cad., No: 4, Topkapı, 34010 İstanbul, Turkey Phone: +90 2123382614 E-mail: foflaz@yahoo.com ORCID: 0000-0002-3878-028X

Submitted Date: June 16, 2020 Accepted Date: August 16, 2021 Available Online Date: September 30, 2021

${ }^{\circ}$ Copyright 2021 by Journal of Psychiatric Nursing - Available online at www.phdergi.org 


\section{What is presently known on this subject?}

- Although the roles and responsibilities of psychiatric nurses have been defined, the difficulties and daily workplace experience of these critical caregivers has yet to be thoroughly studied.

What does this article add to the existing knowledge?

- Psychiatric nurses often still perform a very traditional role in which their daily work is not sufficiently focused on the individual or recovery. There are no standardized staffing criteria for nurses in psychiatric inpatient units. A thorough investigation of the distinct therapeutic aspects of nursing care in psychiatric units to determine the ideal patient/nurse ratio is needed. Despite many challenges in their work environment, nurses largely reported satisfaction with work in psychiatric services.

What are the implications for practice?

- The results of this study are a contribution to the ability to further define the therapeutic roles of psychiatric nurses. Greater knowledge and understanding of the problems these professionals face and the incorporation of solutions could help to ensure quality care and greater professional satisfaction.

ifications of physicians. Profile studies of mental health professionals regarding the number and qualifications of nurses are deficient, ${ }^{[7-11]}$ while these individuals are the main component of inpatient psychiatric care and other mental health services all over the world. This lack of attention and respect is one component that hampers optimal planning for mental healthcare and prevents the generation and implementation of desired and expected outcomes.

\section{Background}

Psychiatric services in Turkey are primarily provided by regional hospitals and at community mental health centers (CMHCs) affiliated with these hospitals. The majority of nurses working in psychiatric services have a bachelor's degree in general nursing. Nurses with a master's and a doctorate degree in psychiatric nursing can use the title "psychiatric nurse" and pursue psychotherapy training. Nurses starting their careers in the field of psychiatry are generally state employees or fulfilling a temporary assignment within their institution. While in this role, nursing staff work at psychiatric inpatient units, and may also perform a therapeutic role in outpatient clinics, consultation-liaison units, addiction treatment centers, retirement homes, child monitoring centers, and other service areas. The roles and responsibilities expected of nurses vary by province, specific group, and the hospital and management team..$^{[12-15]}$

According to statistics provided by the Ministry of Health of Turkey (2017), the average number of nurses for each 1000 individuals is much lower than in EU countries (1.96 vs. 8.23). ${ }^{[16]}$ Despite rapid changes in the policies and types of services provided in the field of mental health, information about the numbers and qualifications of nurses working in psychiatric services is lacking. At the time of writing, only the National Mental Health Action Plan, published in 2011, included the number of nurses working in the psychiatric field, and provided no additional detailed information. ${ }^{[15]}$

The lack of data on the quantity and quality of the nursing workforce in psychiatric services has contributed to a failure to establish standards of care and thus the failure to provide adequate nursing care that focuses on the needs of the service users. ${ }^{[17]} \mathrm{A}$ comprehensive examination of nursing staff that includes the quantity, education, and abilities; the units they work in, and the responsibilities they undertake will facilitate the identification and treatment of problems in mental health service care. This study was designed to investigate the professional, educational, and workplace-related conditions and characteristics of psychiatric nursing staff in order to add to our current knowledge.

The specific aims of the study were to determine the characteristics, activities, and problems of nurses working in psychiatric units:

- What are the demographic and professional characteristics (such as education, experience, work area, and working conditions) of nurses working in psychiatric units?

- What are the views of nurses working in psychiatric units about the field of psychiatry?

- What problems do nurses working in psychiatric units face?

- What is the status of support for educational and scientific activities for nurses working in psychiatric units?

\section{Materials and Method}

\section{Design and Setting}

This descriptive and cross-sectional study was conducted using data from psychiatric hospitals and affiliated institutions, such as CMHCs and centers for addiction treatment services in Istanbul. Istanbul is a large city that provides all levels of mental health services, including 2 large, major psychiatric hospitals, as well as psychiatric inpatient units and outpatients in university and state hospitals, and private psychiatric hospitals. Therefore, a study conducted in Istanbul could provide valuable representative information about the variety of services offered throughout the country. ${ }^{[15,18]}$

\section{Participants}

The population of the study consisted of 548 nurses working in psychiatric hospitals and affiliates (Table 1). Inclusion criteria for the study were current employment in the psychiatric units of psychiatric and other hospitals in Istanbul and willingness to participate in the research. There were no exclusion criteria. All nurses working in these institutions were contacted and invited to enroll in the study by the researchers. The minimum necessary sample size was calculated to be 226 based on a 0.05 significance level and a $95 \%$ confidence level (https://www.surveysystem.com/sscalc.htm\#one; Creative Research Systems, Inc., Sebastopol, CA, USA). In all, 307 nurses participated in this study.

\section{Data Collection}

Data were collected using a 46-question digital survey between October 2017 and July 2019. The survey included per- 
Table 1. Psychiatric and mental health hospitals in Istanbul: Number of nurses and bed capacity

\begin{tabular}{lcc} 
Hospital & Nurse population* & Bed capacity \\
\hline State psychiatric and mental health hospitals & 367 & 1421 \\
Psychiatric departments of university and state general hospitals & 70 & 165 \\
Private psychiatric and mental health hospitals & 111 & 367 \\
Total & 548 & 1953 \\
\hline
\end{tabular}

*The number of nurses was provided by the administrative units of the hospitals surveyed.

sonal (age, education, marital status, institution and unit type, years of experience in psychiatry, etc.) and work-related characteristics (tasks and responsibilities, problem areas, participation in scientific activities, etc.). ${ }^{[9,19-21]}$ The survey was sent to the participants via email. The researchers collaborated with the charge nurses and chief nurses at the facilities. Faceto-face meetings were conducted at institutions where data could not be collected via email.

\section{Data Analysis}

Descriptive statistics (frequency, percentage, arithmetical mean and range) were used to describe the participants' profiles and a chi-squared test was used to assess comparisons with IBM SPSS Statistics for Windows, Version 26.0 (IBM Corp., Armonk, NY, USA).

\section{Ethical Considerations}

Ethical approval was granted by the Koç University Ethics Committee (No: 2017.150.IRB3.076) and each participant provided written consent as part of the online survey process. The study was conducted in accordance with the Helsinki Declaration; confidentiality was maintained throughout, and the personal information of all the participants was no disclosed at any time.

\section{Results}

The majority of the study nurses were female and worked in state hospitals. The average age of the participants was $32.29 \pm 9.82$ years, and $55 \%$ were single. Some educational and work-related characteristics are displayed in Table 2. Only $16.9 \%$ of the nurses in the study had received psychotherapy training. The content of this psychotherapy training was primarily limited to family therapy, sex therapy, group therapy, art therapy, and cognitive behavioral therapy. The nurses reported that the average number of patients that they cared for was 22.03 \pm 13.60 (min-max: 4-79). However, $79.4 \%$ believed that the ideal patient/nurse ratio should be 1 nurse to every 2-5 patients. Nearly half of the nurses polled reported no known assignment criteria for a unit or nurse/patient ratio. Reported nursing activities are displayed in Table 3.

The most common problems stated by the nurses surveyed were an inadequate physical environment, insufficient nurs- ing staff, and the lack of reimbursement for nursing initiatives. In state hospitals $83.9 \%$ of respondents reported that the physical environment was not appropriate, while $85 \%$ of those in university/public hospitals units, and $53.2 \%$ of nurses in private hospitals expressed a similar sentiment $\left(X^{2}: 27.342\right.$; $p=.001$ ). Despite this, $86.6 \%$ reported that they were satisfied with working in psychiatry; however, when asked about their future plans, only $30 \%$ stated that they want to continue as a psychiatric nurse (Table 4).

Table 5 illustrates the nurses' education level and the type of institution they worked in. There were more nurses with a bachelor's degree or graduate degrees ( $\left.X^{2}: 22.541 ; p=.001\right)$ and fewer graduate-level trained nurses $\left(X^{2}: 9.356 ; p=.009\right)$ in the state psychiatric and mental health hospitals. Satisfaction related to working in psychiatry did not differ significantly according to institution type $\left(X^{2}: 5.761 ; p=.056\right)$, though nurses employed at private hospitals seemed more satisfied with the institution ( $\left.X^{2}: 6.930, p=.031\right)$. The nurses at private hospitals were also significantly younger than those who worked at state hospitals (F: 3.515; $\mathrm{p}=.031$ ). There were no significant differences in the number of patients or the patient-nurse ratio between institution types.

Table 6 displays the comparisons of the problems reported by the nurses, and institutions types. Generally, fewer problems were reported by those working at private hospitals. Insufficient support and security personnel, nursing staff, safety protocols, role descriptions, and inappropriate physical environment were reported mostly by nurses who worked in the psychiatric units of state and university hospitals.

The reported ratio of participation in scientific activities, such congresses or/and symposiums was very low. The most common reasons for not participating were the inability to find sponsors (58\%), lack of staff (44\%), non-supportive management (35.8\%), and lack of time (40\%).

\section{Discussion}

One of the only components that does not change in the constantly and rapidly changing field of healthcare is the need for adequate, qualified nursing care. However, although the majority of service providers in psychiatric care are nurses, there is a lack of detailed information about their characteristics. Therefore, the results of this study will not only provide useful 
Table 2. The education and work-related characteristics of psychiatric nursing staff

\begin{tabular}{|c|c|c|c|c|c|}
\hline & (Min-Max) & Mean & SD & $\mathbf{n}$ & $\%$ \\
\hline Years of professional nursing experience & $(1-38)$ & 10.24 & 10.21 & & \\
\hline Years of experience in psychiatric services & $(1-38)$ & 6.87 & 8.51 & & \\
\hline Age (years) & $(19-60)$ & 32.29 & 9.82 & & \\
\hline \multicolumn{6}{|l|}{ Education } \\
\hline Baccalaureate degree & & & & 174 & 56.7 \\
\hline Master's degree/doctorate & & & & 48 & 15.6 \\
\hline \multicolumn{6}{|l|}{ Field of basic educational program } \\
\hline Nursing & & & & 258 & 84.3 \\
\hline Midwifery & & & & 8 & 2.6 \\
\hline Psychiatric nursing & & & & 53 & 72.6 \\
\hline Other (health management, etc.) & & & & 20 & 27.3 \\
\hline \multicolumn{6}{|l|}{ Type of institution of employment } \\
\hline State psychiatric and mental health hospital & & & & 205 & 66.8 \\
\hline Psychiatric unit of university or state hospital & & & & 40 & 13.0 \\
\hline Private psychiatric and mental health hospital & & & & 62 & 20.2 \\
\hline \multicolumn{6}{|l|}{ Unit of employment } \\
\hline Acute inpatient unit & & & & 132 & 43.0 \\
\hline Chronic inpatient unit & & & & 98 & 31.9 \\
\hline Addiction treatment services & & & & 30 & 9.8 \\
\hline Administrative & & & & 13 & 4.2 \\
\hline \multicolumn{6}{|l|}{ View about nurse /patient ratio } \\
\hline Adequate & & & & 49 & 16.0 \\
\hline Inadequate & & & & 128 & 41.7 \\
\hline Partially adequate & & & & 130 & 42.3 \\
\hline \multicolumn{6}{|l|}{ Criteria for being assigned to a ward/unit** } \\
\hline No certain criteria & & & & 137 & 44.6 \\
\hline According to patient numbers & & & & 136 & 44.3 \\
\hline According to the tasks to be done & & & & 121 & 39.4 \\
\hline According to the nursing care needs of patients & & & & 120 & 39.1 \\
\hline According to the number of subunits & & & & 76 & 24.8 \\
\hline According to a request from the ward chief resident & & & & 60 & 19.5 \\
\hline According to the number of doctors & & & & 8 & 2.6 \\
\hline
\end{tabular}

*Percentage of participants attending graduate programs. ${ }^{* *}$ The number reflects multiple responses. SD: Standard deviation; Min: Minimum; Max: Maximum.

insights into the work conditions and problem areas of psychiatric nursing, but also contribute to future studies.
Most of the participants had graduated from a nursing baccalaureate program. One-fourth had a graduate level education, 
Table 3. Nursing activities and record-keeping tasks according to nurses' statements

\begin{tabular}{|c|c|c|}
\hline & $\mathbf{n}^{*}$ & $\%$ \\
\hline \multicolumn{3}{|l|}{ Nursing activities } \\
\hline $\begin{array}{l}\text { Patient observation (including confinement } \\
\text { and monitoring) }\end{array}$ & 298 & 97.1 \\
\hline $\begin{array}{l}\text { Administration of oral/parenteral medications, } \\
\text { measurement of vital signs, etc. }\end{array}$ & 291 & 94.8 \\
\hline $\begin{array}{l}\text { Preparing and carrying out nursing care plan } \\
\text { according to patient needs }\end{array}$ & 280 & 91.2 \\
\hline $\begin{array}{l}\text { Orientation of patients to the unit } \\
\text { Providing discharge education }\end{array}$ & $\begin{array}{l}267 \\
257\end{array}$ & $\begin{array}{l}87.0 \\
83.7\end{array}$ \\
\hline Accompanying doctors on patient rounds & 266 & 86.6 \\
\hline $\begin{array}{l}\text { Assisting patients with personal hygiene, } \\
\text { eating, dressing, mobility }\end{array}$ & 259 & 84.4 \\
\hline Checking patient room & 255 & 83.1 \\
\hline Relaying doctor's instructions to the patient & 248 & 80.8 \\
\hline Occupational/recreational activities with patients & 242 & 78.8 \\
\hline Gross physical examination of patients & 227 & 73.9 \\
\hline Providing patients with information & 226 & 73.6 \\
\hline Dressing wounds as needed & 213 & 69.4 \\
\hline Group activities with patients & 207 & 67.4 \\
\hline Individual patient counseling & 184 & 59.9 \\
\hline Family counseling & 129 & 42.0 \\
\hline Group work with families & 89 & 29.0 \\
\hline \multicolumn{3}{|l|}{ Record-keeping tasks } \\
\hline Daily patient progress records & 300 & 97.7 \\
\hline Records of vital signs & 300 & 97.7 \\
\hline Nursing care plan details & 299 & 97.4 \\
\hline $\begin{array}{l}\text { Night shift/weekend or holiday on-duty } \\
\text { delivery notes }\end{array}$ & 294 & 95.8 \\
\hline Administration of oral/parenteral medications & 293 & 95.4 \\
\hline Records of patient self-care/hygiene activities & 275 & 89.6 \\
\hline Records of patient personal belongings & 258 & 84.0 \\
\hline Records related to quality assurance system & 212 & 69.1 \\
\hline Statistics related to patient records & 155 & 50.5 \\
\hline \multicolumn{3}{|l|}{ Non-nursing tasks } \\
\hline Opening and closing the service doors & 188 & 61.2 \\
\hline Follow-up of medical tests results & 184 & 59.9 \\
\hline Management of supplies & 160 & 52.1 \\
\hline $\begin{array}{l}\text { Activities related to hospital quality } \\
\text { assurance and environment }\end{array}$ & 160 & 52.1 \\
\hline $\begin{array}{l}\text { Dealing with mechanical and infrastructure } \\
\text { problems in the unit }\end{array}$ & 142 & 46.2 \\
\hline Follow-up of patient prescriptions & 124 & 40.4 \\
\hline Hosting managers and their guests & 119 & 38.8 \\
\hline $\begin{array}{l}\text { Secretariat/committee work/patient } \\
\text { admission work }\end{array}$ & 116 & 37.8 \\
\hline Determining and following up on patient diet & 112 & 36.5 \\
\hline
\end{tabular}

*The numbers of nurses who selected that item.

and $16.9 \%$ had some kind of psychotherapy training, at different levels. The title of psychiatric nurse is granted to nurses holding a master of science or a doctorate degree in Turkey.
Table 4. Nurses' views about problem areas, employment conditions, and their future plans

\begin{tabular}{|c|c|c|}
\hline & $\mathbf{n}^{*}$ & $\%$ \\
\hline \multicolumn{3}{|l|}{ Issues considered a problem } \\
\hline Inappropriate physical environment & 239 & 77.9 \\
\hline Insufficient nursing staff & 237 & 77.2 \\
\hline $\begin{array}{l}\text { Nursing interventions not eligible for } \\
\text { reimbursement }\end{array}$ & 236 & 76.9 \\
\hline $\begin{array}{l}\text { Insufficient standards to ensure patient and } \\
\text { employee safety }\end{array}$ & 218 & 71.0 \\
\hline Insufficient support staff (nursing aids) & 211 & 68.7 \\
\hline Need to perform non-nursing tasks & 198 & 64.5 \\
\hline Insufficient security personnel & 190 & 61.9 \\
\hline $\begin{array}{l}\text { Poor communication between doctors } \\
\text { and patients }\end{array}$ & 172 & 56.0 \\
\hline $\begin{array}{l}\text { Inadequate legal provisions related to } \\
\text { emergency situations (need to perform } \\
\text { unauthorized practices) }\end{array}$ & 170 & 55.4 \\
\hline Inadequate role description as a specialist & 165 & 53.7 \\
\hline Lack of teamwork & 151 & 49.2 \\
\hline Frequent replacements among the units & 145 & 47.2 \\
\hline Inadequate job descriptions & 138 & 45.0 \\
\hline Inadequate care protocols & 116 & 37.8 \\
\hline Inadequate space for patient relatives & 45 & 14.7 \\
\hline \multicolumn{3}{|l|}{ Satisfied with working in psychiatry } \\
\hline Yes & 266 & 86.6 \\
\hline No & 41 & 13.4 \\
\hline \multicolumn{3}{|l|}{ Satisfied with the unit } \\
\hline Yes & 268 & 87.3 \\
\hline No & 39 & 12.7 \\
\hline \multicolumn{3}{|l|}{ Future plans } \\
\hline Continuing as a psychiatric nurse & 92 & 30.0 \\
\hline Attending a graduate/PhD program & 70 & 22.8 \\
\hline Academia & 48 & 15.6 \\
\hline Retirement & 39 & 12.7 \\
\hline Transfer to another institution & 22 & 7.2 \\
\hline Transfer to another profession & 14 & 4.6 \\
\hline Leaving current job & 11 & 3.6 \\
\hline Transfer to a unit other than psychiatry & 6 & 2.0 \\
\hline
\end{tabular}

* The number of nurses who selected that item.

According to profile studies and research, in countries besides those with well-developed psychiatry services (e.g., UK, USA, and Australia), the number of nurses that have acquired this title in other countries is as low as in Turkey. ${ }^{[22,23]}$ The fact that nurses perform psychiatric care and related services without a specialization in psychiatry is one of the factors that negatively affects teamwork and the quality of care. Moreover, the low number of specialized nurses in psychiatry has resulted to a weakness in the relevant research, institutional planning, and broader policymaking. ${ }^{[9,10,19-21]}$

It has been established that patients have better outcomes as the quantity and quality of nurses increases in general health 
Table 5. Comparison of the institution type and some characteristics of the study participants

\begin{tabular}{|c|c|c|c|c|c|c|c|}
\hline & \multicolumn{2}{|c|}{$\begin{array}{l}\text { State PMH } \\
\text { hospital }\end{array}$} & \multicolumn{2}{|c|}{$\begin{array}{c}\text { Psychiatric unit of } \\
\text { university/state } \\
\text { hospital }\end{array}$} & \multicolumn{2}{|c|}{$\begin{array}{c}\text { Private } \\
\text { PMH hospital }\end{array}$} & \multirow[t]{2}{*}{$\begin{array}{c}\mathbf{X}^{2} \\
\mathbf{p}\end{array}$} \\
\hline & $\mathbf{n}$ & $\%^{*}$ & $\mathbf{n}$ & \%* & $\mathbf{n}$ & $\%^{*}$ & \\
\hline \multicolumn{8}{|l|}{ Education level } \\
\hline High school & 13 & 6.3 & 3 & 7.5 & 14 & 22.6 & $22.541 /$ \\
\hline Associate degree & 38 & 18.5 & 5 & 12.5 & 12 & 19.4 & .001 \\
\hline Bachelor's degree & 126 & 61.5 & 20 & 50.0 & 28 & 45.2 & \\
\hline Postgraduate & 28 & 13.7 & 12 & 30.0 & 8 & 12.9 & \\
\hline \multicolumn{8}{|l|}{ Graduate education } \\
\hline Yes & 41 & 20.0 & 15 & 24.2 & 17 & 42.5 & 9.356 \\
\hline No & 164 & 80.0 & 47 & 75.8 & 23 & 57.5 & .009 \\
\hline \multicolumn{8}{|c|}{ Satisfied with psychiatry career } \\
\hline Yes & 171 & 83.4 & 38 & 95.0 & 57 & 91.9 & 5.761 \\
\hline No & 34 & 16.6 & 2 & 5.0 & 5 & 8.1 & .056 \\
\hline \multicolumn{8}{|c|}{ Satisfied with current employer } \\
\hline Yes & 160 & 78.0 & 28 & 70.0 & 56 & 90.3 & 6.930 \\
\hline \multirow[t]{2}{*}{ No } & 45 & 22.0 & 12 & 30.0 & 6 & 9.7 & .031 \\
\hline & \multicolumn{2}{|c|}{ Mean $\pm S D$} & \multicolumn{2}{|c|}{ Mean $\pm S D$} & \multicolumn{2}{|c|}{ Mean $\pm S D$} & F/p \\
\hline Age (years) & \multicolumn{2}{|c|}{$33.02 \pm 10.36^{*}$} & \multicolumn{2}{|c|}{$33.08 \pm 8.11$} & \multicolumn{2}{|c|}{$29.35 \pm 8.49^{*}$} & $3.515 / .031$ \\
\hline
\end{tabular}

* Colon \%. PMH: Psychiatric/mental health; SD: Standard deviation.

settings, ${ }^{[1-3]}$ but additional evidence specific to psychiatric care is needed. It is important that nurses have sufficient professional experience and education in order to properly perform their role and effectively shape the therapeutic environment. ${ }^{[24]}$ Our results revealed an average length of experience of nurses in psychiatric units was 6-8 years. As Benner has explained, 6-10 years of work experience indicates that nurses are competent and efficient in making the right decisions, forecasting, and seeing what is not readily seen. That is, work experience provides confidence that nurses can generally make correct and efficient decisions. However, examination of educational differences among the nurses suggests that private hospitals appear to hire more diploma and associate degree level nurses in psychiatric units. Yet, studies have indicated that the mortality rate, duration of hospital stay, and readmission to hospital after discharge decrease when the majority of nurses in general medical units have a baccalaureate degree. ${ }^{[1-3]}$ This is why we need more evidence about the outcomes of psychiatric nursing care, in order to provide sufficiently qualified staffing.

In this study, the nurses surveyed stated that they care for approximately 22 patients, and indicated that they thought the ideal ratio is 1 nurse per $2-5$ patients. The relevant literature also states that nurses in acute wards should be required to care for fewer patients (6/1).[.] There are no formal regulations or specific criteria that identify the patient/nurse ratio in psychiatric services in Turkey. ${ }^{[3,25]}$ Moreover, there are also no cri- teria governing the placement of nurses in psychiatric units. This is a substantial matter for future studies to ensure the quality of psychiatric care and represents an obstacle to the achievement of optimal psychiatric care.

Cowman et al. (2001) stated that nurses perform tasks such as assessing patient needs, maintaining effective communication, conducting educational activities, maintaining records, and organizing and coordinating the unit environment. ${ }^{[26]}$ In this study, nurses noted that they spend time administering medicines, making observations, managing diagnostic test processes, developing care plans, interviewing patients, providing education, and performing coordination duties. Ergün et al. ${ }^{[27]}$ and Ünsal et al. ${ }^{[28]}$ also reported similar activities in their studies that reflect a common biomedical role. Cutcliffe et al. ${ }^{[29]}$ discussed the fact that psychiatric nursing is still included within classical and biological nursing with a focus on symptoms, treatment compliance, measures to prevent selfharm or harm to others, and implementing necessary control mechanisms.

The fact that the nurses allocated little time to patients' families is another significant finding of this research. Nurse contact with family members and relatives is generally limited to visiting hours, and there is a lack of regular and systematic support programs for families. In Turkey, the inadequacy of psychosocial interventions might be associated with a lack of training about these kinds of interventions and a lack of financial support for nurses to attend psychotherapeutic training 
Table 6. Comparison of institution type and problems reported by the study participants

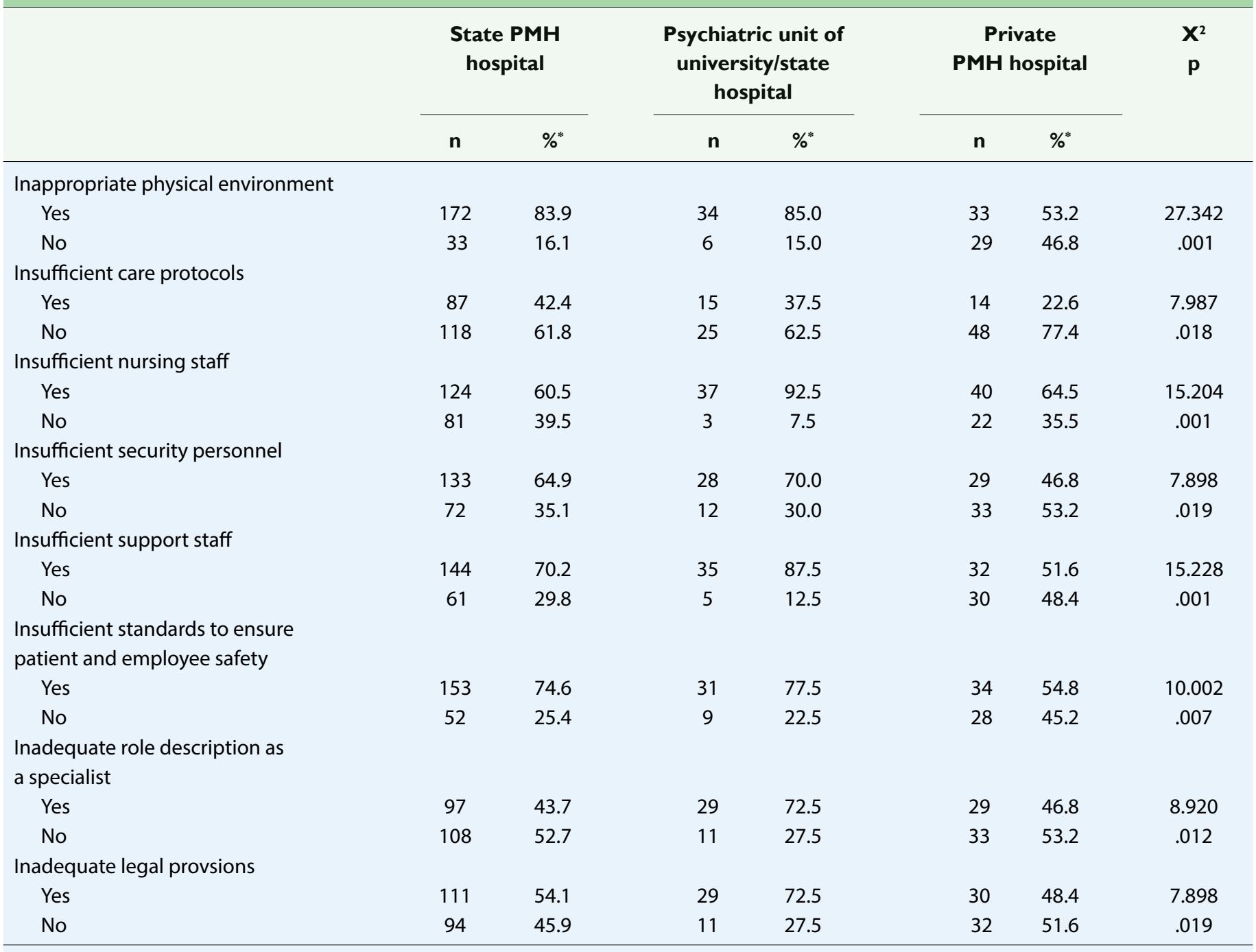

*Colon \%. PMH: Psychiatric/mental health.

programs. In addition, the higher nurse-patient ratio may be important as a contributing factor. It is recommended in the USA that the nurse/patient ratio in psychiatry wards should not exceed 1:6. The number of nurses in Turkey is still inadequate not only in psychiatry but in general. ${ }^{[15,16,30]}$

According to the modern approach to psychiatry, psychosocial therapies are a key element of psychiatric treatment. However, in Turkey, there is no regulation that enables nurses to conduct such psychosocial interventions, even if they have had adequate training. This is common in psychiatric services in many countries ${ }^{[19,29,31]}$ Ergün et al. ${ }^{[27]}$ stated that nurses had no responsibility in group therapies, yet psychoeducation in psychiatry units is typically either administered by nurses or not provided at all. ${ }^{[32]}$ Ünsal et al. ${ }^{[28]}$ identified some psychosocial activities, such as occupational therapy and "good morning meetings" as nurses' roles. Although some therapeutic activities have been identified for use in psychiatric units, as noted by McAllister and McCrae, ${ }^{[6]}$ the lack of definition or es- tablished practices of therapeutic engagement can often be a problem. Having no financial and regulatory support for psychosocial therapeutic interventions may well be related to the lack of training about these kinds of interventions and resulting lack of provision of this valuable part of care. ${ }^{[22]}$ Nurses may not feel competent to perform to these therapeutic interventions and for this reason they may focus on traditional roles. Also, disinclination to engage in these activities may also be a result of the regulations of the institution.

The findings of this study demonstrated that not only is the number of nurses insufficient and that they perform very classic care roles, but also that they carry out non-nursing tasks, as in the past. These non-nursing tasks are duties not included in job descriptions and decrease the time spent on patient care. Records kept by nurses also showed that they deal with prescription procedures, statistics, medical test processes, and quality assurance systems. Such additional unrelated duties contribute to workforce loss in nursing care. ${ }^{[14,33]}$ The results 
highlight the existence of a traditional image of nursing and biomedical practices instead of an emphasis on an integrative approach that facilitates and supports recovery in mental health. Stewart et al. ${ }^{[5]}$ noted that patients need more qualified interactions with nurses. In their study, patients were concerned that the nurses were too busy with paperwork and did not spend sufficient time with the patients.

Nurses in psychiatry, as in other fields, also play a role in coordinating the activities of other health professionals to ensure the continuity of patient care. ${ }^{[26]}$ However, this coordination role, which remains undefined in job descriptions, can take too much of the nurses' time, especially in psychiatric care wards, and can lead to problems due to a lack of definitions. ${ }^{[34]}$ Some problems observed in our study may be related to that particular role. The lack of sufficient nursing staff lies at the core of all of the problems and the lack of sufficient support personnel further perpetuates the problems.

The majority of nurses in this study reported an inappropriate physical environment, a lack of necessary security standards, insufficient nursing staff, non-differentiation in pay with regard to roles and tasks, and a lack of support personnel as problems they encountered. A lack of personnel, safety protocols, role descriptions, and an appropriate physical environment were reported most by the nurses who worked in the psychiatric units of state and university hospitals. The level of dissatisfaction was generally lower among the nurses who worked in private hospitals. The conditions at psychiatry units in state hospitals are still not at the desired level in Turkey. Hospital buildings are generally old and inadequate for the provision of a comfortable venue for employees or patients. Security issues also increase under these conditions. ${ }^{[25,27,35-38]}$ Similarly, Shattel et al. ${ }^{[39]}$ reported that both patients and nurses perceived the psychiatric environment as a cage. Haines et al. ${ }^{[40]}$ also observed that the perception of safety among the staff was associated with the physical environment and aggression within the workplace. Every person in the work environment has the right to feel safe and efforts to reorganize the physical environment may help to reduce workplace stress. ${ }^{[41]}$

Despite the problems they encountered, the nurses surveyed were generally satisfied with working in psychiatric services. Nurses working in private institutions had a higher level of satisfaction with their institution than nurses working in university/state hospitals. One reason may be having the choice to work in that facility, in addition to the inferior conditions in other hospitals. One of the reasons may be choosing to work in that private facilities by their personal choice, in addition to the insufficient conditions in state/university hospitals. The issues of insufficient staff and equipment have been a common problem in university hospitals in recent years because of economic restrictions and other social factors. Similar problems in public hospitals were noted by Manyisa et al. ${ }^{[42]}$ They observed that an excessive workload, long working hours, poor working conditions, poor infrastructure, inadequate resources, a lack of safety and security, not being involved in the decision-making process, and a lack of support were among the main factors attributed to poor working conditions in public hospitals.

The number of nurses in this study who planned to change units, institutions, or profession was quite low. Since psychiatric care focuses on individuals more than medical procedures, nurses may feel more satisfaction in this field. Our findings were consistent with previous studies on satisfaction and burnout. ${ }^{[28,43-47]}$

Only about a quarter of the nurses surveyed had been able to participate in a scientific activity in the previous 2 years. The most common reasons were the inability to find sponsorship, a lack of personnel, non-supportive management, and a lack of time. Similarly, Ünsal et al. ${ }^{[28]}$ found that $77.8 \%$ of nurses did not participate in scientific research. Since nursing organizations are not strong enough to support nurses' participation in such activities, and the institutions they work for often don't recognize nursing as a scientific discipline, policies and regulations are needed to support greater nurse participation in research activities.

\section{Study Limitations}

This study was limited to nurses working in Istanbul. Close-ended survey questions might have restricted their responses. We recommend additional qualitative research using the observation method to learn more details about the workload and activities of nurses working in psychiatric care units.

\section{Conclusion}

The results of this study mirror both current and long-standing deficiencies in psychiatric nursing practice. The findings indicated that psychiatric nurses often still perform a traditional role and their work is not sufficiently focused on recovery. There are no standardized staffing criteria for nurses in psychiatric inpatient units. The results of this study could help decision-makers in a review of the current circumstances in order to assess the tasks, authority, and responsibilities of nurses. Policy development and implementation related to conditions of psychiatric nursing employment and work conditions are needed.

Suggestions based on our findings:

Nursing care activities need to be focused on recovery, with an emphasis on individual-centered need. Nurse employment should be consistent with international and other existing norms and criteria. Additional studies exploring workload in psychiatry units, psychiatric patients dependency level, and so on are needed.

\section{Implications for Practice}

Nursing practices and interventions need to be described in detail in terms of both quality and quantity in order to promote health and enhance service quality in psychiatric facilities. Our findings showed that psychiatric nursing continues 
to be conducted using a traditional role. Additional studies that investigate the distinctive and therapeutic aspects of psychiatric nursing care and provide evidence for the ideal patient/nurse ratio, among other factors, could improve care and outcomes, as well as benefit the morale of nursing staff.

Conflict of interest: There are no relevant conflicts of interest to disclose.

Peer-review: Externally peer-reviewed.

Authorship contributions: Concept - F.O., S.Y., N.E.B., Ö.S., N.D., S.E.; Design - F.O., S.Y., N.E.B., Ö.S., N.D.; Supervision - F.O., S.Y.; Data collection \&/or processing - .O., S.Y., N.E.B., Ö.S., N.D., S.E.; Analysis and/or interpretation - F.O., S.Y., N.E.B., Ö.S.; Literature search - F.O., S.Y., N.E.B., Ö.S.; Writing - F.O., S.Y., N.E.B., Ö.S.; Critical review - F.O., S.Y., N.E.B., Ö.S., N.D.

\section{References}

1. Bal MD. Nursing manpower planning approaches in hospital. Journal of Health and Nursing Management 2014;3:148-54.

2. Lang TA, Hodge M, Olson V, Romano PS, Kravitz RL. Nurse-patient ratios: a systematic review on the effects of nurse staffing on patient, nurse employee, and hospital outcomes. J Nurs Adm 2004;34:326-37.

3. Türkmen E. The relationship between nurse staffing and patient, nurse and organizational outcomes: nurse workforce planning at acute care hospitals. Journal of Hacettepe University Faculty of Nursing 2015;2:69-80.

4. Cleary M, Hunt GE, Horsfall J, Deacon M. Nurse-patient interaction in acute adult inpatient mental health units: A review and synthesis of qualitative studies. Issues Ment Health Nurs 2012;33:66-79.

5. Stewart D, Burrow H, Duckworth A, Dhillon J, Fife S, Kelly S, et al. Thematic analysis of psychiatric patients' perceptions of nursing staff. Int J Ment Health Nurs 2015;24:82-90.

6. McAllister S, McCrae N. The therapeutic role of mental health nurses in psychiatric intensive care: a mixed-methods investigation in an inner-city mental health service. J Psychiatr Ment Health Nurs 2017;24:491-502.

7. Chaskel R, Gaviria SL, Espinel Z, Taborda E, Vanegas R, Shultz JM. Mental health in Colombia. BJPsych Int 2015;12:95-7.

8. Luitel NP, Jordans MJ, Adhikari A, Upadhaya N, Hanlon C, Lund $\mathrm{C}$, Komproe IH. Mental health care in Nepal: current situation and challenges for development of a district mental health care plan. Confl Health 2015;9:3.

9. Ndyanabangi S, Basangwa D, Lutakome J, Mubiru C. Uganda mental health country profile. Int Rev Psychiatry 2004;16:5462.

10. Okasha A, Karam E, Okasha T. Mental health services in the Arab world. World Psychiatry 2012;11:52-4.

11. Rathod S, Pinninti N, Irfan M, Gorczynski P, Rathod P, Gega L, et al. Mental Health Service Provision in Low- and Middle-Income Countries. Health Serv Insights 2017;10:1178632917694350.

12. Kane CF. The 2014 scope and standards of practice for psychiatric mental health nursing: key updates. Online J Issues Nurs 2015;20:1.
13. Özbaş D, Buzlu S. Psychiatric nursing from past to present day. iÜFN Hem Derg 2011;19:187-93.

14. Terakye G, Oflaz F. A historical overview of psychiatric mental health nursing in Turkey. Int J Ment Health 2007;36:73-83.

15. Ministry of Health of the Republic of Turkey (2011) National Mental Health Action Plan / 2011-2023. Available at: 2020 from https://cankirirsp.files.wordpress.com/2017/10/ulusal-ruh-sac49flc4b1c49fc4b1-eylem-planc4b1-2011-2023.pdf. Accessed on: August 8, 2020.

16. Turkey Ministry of Health (2017). Annual statistics on health. Available at: https://www.saglikaktuel.com/d/file/28310, saglik-istatistikleri-yilligi-2017pdf.pdf. Accessed on November 3, 2020.

17. Moyo N, Jones M, Kushemererwa D, Pantha S, Gilbert S, Romero $L$, et al. The association between the mental health nurse-to-registered nurse ratio and patient outcomes in psychiatric inpatient wards: a systematic review. Int J Environ Res Public Health 2020;17:6890.

18. Songur C, Saylavcı E, Kıran Ş. A comparative examination of mental health services on Europe and Turkey. Social Sciences Studies Journal 2017;3:276-89.

19. Khandelwal SK, Jhingan HP, Ramesh S, Gupta RK, Srivastava VK. India mental health country profile. Int Rev Psychiatry 2004;16:126-41.

20. Mayeya J, Chazulwa R, Mayeya PN, Mbewe E, Magolo LM, Kasisi F, et al. Zambia mental health country profile. Int Rev Psychiatry 2004;16:63-72.

21. Sharashidze M, Naneishvili G, Silagadze T, Begiashvili A, Sulaberidze B, Beria Z. Georgia mental health country profile. Int Rev Psychiatry 2004;16:107-16.

22. Horatio: European psychiatric nurses (July2012). Psychiat$\mathrm{ric} /$ mental health nursing and psychotherapy: The position of Horatio: European Psychiatric Nurses. Avaialble at: http:// www.horatio-web.eu/downloads/Psychotherapy_position_ paper.pdf. Accessed on August 26, 2019.

23. Rolewicz L, Palmer B. (08 May 2019). The NHS workforce in numbers. Available at: https://www.nuffieldtrust.org.uk/resource/the-nhs-workforce-in-numbers\#7-how-do-we-compare-to-other-countries. Accessed on =ct0ber 26, 2019.

24. Gerolamo AM. An exploratory analysis of the relationship between psychiatric nurses' perceptions of workload and unit activity. Arch Psychiatr Nurs 2009;23:243-50.

25. Tuna R. Creation of patient classification system and planning of nurse manpower: A study involving outpatient treatment unit of oncology clinic. [Unpublished doctorial thesis] Istanbul: Istanbul University Health Sciences Institute, 2014.

26. Cowman S, Farrelly M, Gilheany P. An examination of the role and function of psychiatric nurses in clinical practice in Ireland. J Adv Nurs 2001; 34:745-53.

27. Ergün G, Işık I, Dikeç G. Roles of psychiatry nurses within a therapeutic environment of psychiatry clinics in Turkey. Arch Psychiatr Nurs 2017;31:248-55.

28. Ünsal G, Karaca S, Arnik M, Öz YC, Aşık E, Kızılkaya M, et al. The opinions of nurses who work in psychiatry clinics related to the roles of psychiatry nurses. Marmara Üniversitesi Sağlık 
Bilimleri Enstitüsü Dergisi 2014;4:90-5.

29. Cutcliffe JR, Stevenson C, Lakeman R. Oxymoronic or Synergistic: Deconstructing the Psychiatric and/or Mental Health Nurse in European Psychiatric. In: Santos JC, Cutcliffe RJ, editors. Mental Health Nursing in the 21st Century: A Person-Centered Evidence-Based Approach. Switzerland: Springer International Publishing; 2018. p. 13-28.

30. Health experts debate the merits of nurse-staffing ratio law. Available at: https://www.nursinglicensure.org/articles/ nurse-staffing-ratios/. Accessed on 1 January, 122021.

31. Demirkıran F. Psychiatric mental health nursing and psychotherapy practices. Turkiye Klinikleri J Psychiatr Nurs-Special Topics 2016;2:1-8.

32. Duran S, Gürhan N. Evaluation of state of acquiring discharge education in psychiatric patients. Firat Univ Med J Health Sci 2012; 26:39-44.

33. Kıran B, Taşkıran EG. Overview of nursing education and manpower planning in Turkey. Lokman Hekim Journal 2015;5:628.

34. Van Bogaert $P$, Clarke S, Willems R, Mondelaers M. Staff engagement as a target for managing work environments in psychiatric hospitals: implications for workforce stability and quality of care. J Clin Nurs 2012;22:1717-28.

35. Öztürk E. Comparison of patients and staff nurses psychiatric ward atmosphere perceptions and factors. [Unpublished master thesis] Izmir: Ege University Health Sciences Institute, 2011.

36. Konstantinos N, Christina O. Factors influencing stress and job satisfaction of nurses working in psychiatric units: a research review. Health Sci J 2008;2:183-195.

37. Ward M, Cowman S. Job satisfaction in psychiatric nursing. J Psychiatr Ment Health Nurs 2007;14:454-61.
38. Özkan Ş, Uydacı M. Determining nurse workforce requirement based on workload in the public hospitals. Journal of Heath and Nursing Management 2020;3:339-51.

39. Shattell MM, Andes M, Thomas SP. How patients and nurses experience the acute care psychiatric environment. Nurs Inq 2008;15:242-50.

40. Haines A, Brown A, McCabe R, Rogerson M, Whittington R. Factors impacting perceived safety among staff working on mental health wards. BJPsych Open 2017;3:204-11.

41. Ulrich RS, Bogren L, Gardiner SK, Lundin S. Psychiatric ward design can reduce aggressive behavior. J Envir Psychol 2018;57:53-66.

42. Manyisa ZM, van Aswegen EJ. Factors affecting working conditions in public hospitals: a literature review. Int J Africa Nurs Sci 2017;6:28-38.

43. Holmberg C, Caro J, Sobis I. Job satisfaction among Swedish mental health nursing personnel: Revisiting the two-factor theory. Int J Ment Health Nurs 2018;27:581-92.

44. Austrom MG, Carvell CA, Alder CA, Gao S, Boustani M, LaMantia M. Workforce development to provide person-centered care. Aging Ment Health 2016;20:781-92.

45. Hezer M. Evaluation of nurses 'satisfaction and burnout levels and nursing care quality. [Unpublished master thesis] Istanbul: Biruni University Health Sciences Institute, 2019.

46. Tekir Ö, Çevik C, Arık S, Çetin G. Examining health workers' burnout, job satisfaction levels and life satisfaction. The Journal of Kırıkkale University Faculty of Medicine 2016;18:51-63.

47. Zheng Z, Gangaram P, Xie H, Chua S, Ong SBC, Koh SE. Job satisfaction and resilience in psychiatric nurses: a study at the Institute of Mental Health, Singapore. Int J Ment Health Nurs 2017;26:612-9. 